\title{
Gênero e Gestão Integrada dos Recursos Hídricos e Saneamento: aproximações da realidade cabo-verdiana e brasileira
}

\author{
Gender and Integrated Management of Water Resources and Sanitation: approximations of Cape Verdean and Brazilian \\ reality
}

\section{Karla Emmanuela Ribeiro Hora', Paulo Sergio Scalize², Claudio Alves Furtado ${ }^{3}$, Luis Jorge Monteiro Fernandes ${ }^{4}$}

'Doutora, Professora Adjunta da Escola de Engenharia Civil da UFG

${ }^{2}$ Doutor. Professor adjunto da Escola de Engenharia Civil da Universdidade Federal de Goiás. Coordenador do curso de Engenharia Civil e ${ }^{3}$ Professor do Curso de Mestrado em Engenharia Ambiental e Sanitária (PPGEAS) e do Programa em Ciências Ambientais (CIAMB)

Universidade Federal da Bahia e Universidade e Universidade de Cabo Verde (UniCV), Cabo Verde

${ }^{4}$ Universidade e Universidade de Cabo Verde (UniCV), Cabo Verde

\begin{abstract}
Resumo
A precariedade do saneamento contribui para agravar a situação de vulnerabilidade social em que muitas mulheres se encontram, destacandose aquelas inseridas nas periferias urbanas, nas comunidades rurais ou nos assentamentos precários. Para superar tais situações, alternativas têm sido adotadas e debatidas em pequenas comunidades e/ou agrupamentos rurais e em áreas peri-urbanas no sentido de favorecer o acesso à água e ao esgotamento sanitário. Grande parte das experiências revela a importância tanto da mobilização social quanto das comunidades locais e, principalmente, da participação ativa das mulheres nos processos de gestão integrada dos recursos hídricos. Diante de tal cenário, o presente estudo tem por objetivo refletir sobre os processos e os instrumentos de planejamento e gestão integrada dos recursos hídricos e de saneamento que incorporam a dimensão de gênero nos contextos cabo-verdiano e brasileiro. A metodologia baseou-se em visitas de observação em Cabo Verde e em áreas rurais no Estado de Goiás, Brasil.
\end{abstract}

Palavras-chaves: Gênero. Recursos Hídricos. Saneamento. Cabo Verde. Brasil.

\begin{abstract}
The precarity of sanitation contributes to aggravate the situation of social vulnerability in which many women are, especially those located in the urban peripheries, rural communities or precarious settlements. To overcome such situations, alternatives have been adopted and discussed in small communities and/ or in rural groups and in periurban areas, in order to promote acess to water and sanitation. Much of the experience reveals the importance of social mobilization and of local communities but, above all, the active participation of women in the processes of integrated management of water resources. Facing this scenario, this study aims to think over the processes and tools for planning and integrated management of water resources and sanitation, that incorporate the gender's dimension in the Cape Verdean and Brazilian contexts. The methodology was based on observation visits in Cape Verde and in rural areas in the State of Goiás, Brazil.
\end{abstract}

Keywords: Gender. Water Resources. Sanitation. Cape Verde. Brazil. 


\section{INTRODUÇÃO}

A ausência de saneamento e de ações voltadas para o tratamento das águas contribui para agravar a situação de vulnerabilidade social em que muitas mulheres se encontram, principalmente aquelas inseridas nas periferias urbanas, nas comunidades rurais ou nos assentamentos precários. Para superar tais situações, alternativas têm sido adotadas e debatidas em pequenas comunidades e/ou agrupamentos rurais e em áreas peri-urbanas, no sentido de favorecer o acesso à água e ao saneamento.

Grande parte das experiências revela a importância tanto da mobilização social quanto das comunidades locais e, principalmente, da participação ativa das mulheres nos processos de gestão integrada dos recursos hídricos. No Brasil, comunidades rurais no planalto central têm apostado no planejamento ambiental de seus territórios, buscando adequar as infraestruturas às condições naturais do terreno, viabilizando, dentre outros aspectos, o acesso à água; em Cabo Verde, verifica-se a ação da Parceria Nacional para a Água, mobilizando diferentes atores para integração numa ampla rede de articulação social, visando debater soluções para acesso à água de qualidade.

Tais iniciativas têm apontado para a existência de um novo marco legal na área de Gerenciamento de Recursos Hídricos e Saneamento, oportunizando o acesso a populações em condições de maior vulnerabilidade socioambiental.

Diante de tal cenário, o presente estudo tem por objetivo refletir sobre os processos e os instrumentos de planejamento e gestão integrada dos recursos hídricos e de saneamento que incorporam a dimensão de gênero nos contextos cabo-verdiano e brasileiro. Dentre os objetivos específicos, espera-se identificar os mecanismos e procedimentos, adotados pelos órgãos competentes, para planejamento dos recursos hídricos e saneamento, bem como as estratégias utilizadas para incorporação da dimensão de gênero.

\section{METODOLOGIA E INFORMAÇÕES UTILIZADAS}

A pesquisa baseou-se em visitas exploratórias, realizadas por missões de pesquisadores no Brasil e em Cabo Verde. No país africano, foi observado o contexto do setor de água e saneamento e seus reflexos sobre as comunidades locais, em especial sobre as mulheres. Tais observações basearamse nas visitas a comunidades e sistemas locais de operação e gestão em saneamento e na pesquisa de documentos referentes à temática.

No Brasil, dada a amplitude geográfica, optou-se por averiguar a realidade de Goiás, apoiando-se em visitas exploratórias sobre a situação do setor de água e saneamento e seu reflexo sobre comunidades rurais, especificamente as áreas de assentamentos de reforma agrária e suas implicações sobre a vida das mulheres. As atividades ocorreram no primeiro semestre de 2011 e dividiram-se em: visitas às instituições responsáveis pelas políticas de gerenciamento dos recursos hídricos e saneamento local e nacional; visitas aos sistemas de abastecimento e tratamento de água; visitas às comunidades beneficiadas pelos programas de gestão; e participação em reuniões técnicas e atividades acadêmicas, visando o intercâmbio de informações e proposições. As informações foram sistematizadas em formato de relatório e foi proposta uma agenda de pesquisa entre universidades dos dois países, para aprofundamento das questões tratadas.

\section{RESULTADOS E DISCUSSÕES}

\subsection{Cabo Verde e as políticas de gênero}

\section{I.I Aproximando-se de Cabo Verde}

Cabo Verde é um pequeno país africano, com $4033 \mathrm{~km}^{2}$, que está situado no Oceano Atlântico, a cerca de $450 \mathrm{~km}$ da costa oeste africana, na direção do Senegal. O clima é tropical seco, com temperatura média anual entre $24^{\circ} \mathrm{C}$ e $25^{\circ} \mathrm{C}$. O país é caracterizado por um período muito curto de precipitações, com má distribuição temporal e espacial, com prolongados períodos de carência hídrica, solos vulneráveis, tanto do ponto de vista físico quanto do ponto de vista geoquímico, e ausência de cursos de água permanentes. Mesmo nas zonas mais montanhosas, a precipitação média anual não 
ultrapassa os 600 milímetros ao ano. Os recursos naturais tradicionais são raros e apenas $10 \%$ das terras são potencialmente aráveis.

Dados do Censo de 2010, realizado pelo Instituto Nacional de Estatística, indicam que Cabo Verde tinha, nesse ano, 491.5875 habitantes residentes, sendo 40,5\% mulheres (CABO VERDE, 2010). A taxa de crescimento da população é de $1,2 \%$ a.a. em relação a 2000 e a taxa de urbanização é de $61 \%$. Mais de $30 \%$ dos habitantes têm idade menor a 20 anos, o que permite dizer que a população cabo-verdiana é, ainda, maioritariamente jovem.

No que tange ao contexto político-administrativo, Cabo Verde foi colônia portuguesa por cinco séculos e, desde 1991, optou pelo sistema político multipartidário, tendo como sistema de governo o parlamentarismo, por alguns denominado de parlamentarismo mitigado, uma vez que existe uma distribuição de poderes entre o Parlamento, o Governo e o Presidente da República. Neste contexto, procedeu-se à elaboração de uma nova Constituição cujos princípios versam pela soberania, unitária e democrática, garantindo o respeito pela dignidade humana e reconhecendo a inviolabilidade e inalienabilidade dos Direitos do Homem como fundamento de toda a comunidade humana, da paz e da justiça. Administrativamente, o país é composto por um governo central e por 22 governos locais, espalhados pelos municípios que formam a menor unidade administrativa no país.

\subsubsection{Recursos hídricos e saneamento}

Cabo Verde é um pequeno estado insular e seu clima austero faz com que essas ilhas sejam fustigadas por longos períodos de seca e, por conseguinte, com problemas ligados à disponibilidade hídrica, fazendo com que a escassez de água se torne um problema dos mais graves para as populações. Isto resultou, desde muito cedo, na aposta, dos sucessivos Governos, numa política de priorização clara e assumida do setor da água e saneamento.

Nesse cenário, de forma a adaptar às novas exigências de melhoria de indicadores sociais, acompanhando o crescimento econômico que o país vem experimentado nos últimos tempos e das expectativas criadas junto a população, são notórias as mudanças institucionais realizadas; os programas desenvolvidos; e os investimentos em infraestruturas e serviços de exploração e distribuição de água e saneamento, que se traduzem em resultados positivos palpáveis.

O quadro institucional na administração dos recursos hídricos em Cabo Verde considera, como um dos órgãos centrais, o Conselho Nacional de Águas (CNAG), que é um órgão interministerial presidido pelo Ministro do Ambiente, Habitação e Ordenamento do Território. É composto, ainda, pelos Ministros responsáveis pelas áreas da Saúde, Infraestruturas, Indústria e Energia, Autarquias locais e Finanças. Este órgão é responsável pela planificação geral e pela implementação da política setorial, seguindo o programa e o orçamento preparados para o efeito e aprovados pelo Governo. O INGRH (Instituto Nacional de Gestão dos Recursos Hídricos) é o órgão executivo do CNAG e sobre ele recai a responsabilidade de supervisionar e coordenar a planificação, a gestão e o desenvolvimento sustentável do setor dos recursos hídricos a nível nacional. O Instituto tem atribuições e competências específicas em matéria de controle, prevenção e manutenção da qualidade dos recursos hídricos; na elaboração e implementação de planos diretores, atribuições de licenças e autorizações requeridas para a exploração dos recursos subterrâneos destinados ao abastecimento e à irrigação; e pela conservação das infraestruturas de produção de água, nomeadamente furos, poços, barragens e similares. A Agência de Regulação Econômica (ARE) faz a administração econômica do setor.

Constata-se que, ultimamente, com a entrada da iniciativa privada no setor de produção e abastecimento da água potável, assim como com o processo de descentralização e autonomia do setor da água, foram criados os Serviços Autônomos de Água e Saneamento (SAAS) e empresas municipais. Para além disto, destaca-se a concessão feita, a empresas privadas, para a produção e distribuição de água através do processo de dessalinização.

Todas essas ações vêm contribuir de forma significativa para o aumento da disponibilidade de água, para o abastecimento às populações e o incremento das atividades econômicas. Para complementar, está sendo implementado, em nível nacional, um amplo programa de construção de infraestruturas de captação, estocagem de águas superficiais com a construção de barragens e de mobilização das águas subterrâneas através de furos.

Com essa política de investimentos, constata-se uma evolução favorável no setor, que é confirmada pelos dados do QUIBB - Questionário Unificado de Bem-Estar (CABO VERDE, 2006), indicando que a percentagem de população com acesso à água em 1990 era de cerca de 42\%, passando 
para cerca de $85 \%$ em 2006 e devendo atingir os $91 \%$ em 2015. Ainda segundo Furtado e Pires (2008), o inquérito permitiu aferir que cerca de $3 / 4$ das famílias cabo-verdianas tem uma fonte de água a menos de 15 minutos. Mesmo no meio rural, cerca de $77 \%$ das famílias tem água potável e a situação é ainda melhor no meio urbano (93\%). Neste particular, vê-se alcançada uma das metas dos Objetivos do Milênio (ODM) para a água, que é de "reduzir para metade a percentagem da população que não tem o acesso à água potável de forma durável", que no horizonte 2015 seria de $71 \%$.

No subsetor de saneamento, não obstante os investimentos realizados, ainda aspiram-se avançar sobre aspectos de esgotamento sanitário e outros. De acordo com o Censo 2010, a percentagem de agregados familiares que residem em alojamentos com sistema de evacuação de água residuais, seja rede pública de esgotos, seja fossas sépticas, era de $66,9 \%$. Com esse dado, foi cumprido o $7^{\circ}$ ODM, que preconiza que, até $2015,62 \%$ da população deveria ter acesso ao saneamento.

Essa meta está sendo conseguida graças a avultados investimentos em infraestruturas, nomeadamente de construção e expansão de redes públicas de esgoto, construção de unidades coletivas e individuais de sistemas de tratamento. Em relação aos últimos, devem ser realçados os investimentos feitos recentemente na expansão da rede de esgoto e na estação de tratamento das águas residuais da Ilha de São Vicente, em que o aproveitamento das mesmas, segundo Furtado e Pires (2008), garante a irrigação de cerca de 70 ha de terreno que é destinado à prática da agricultura, sendo que um número considerável das parcelas de solo é gerido por mulheres.

\section{I.3 Políticas de Gênero em Recursos Hídricos e Saneamento}

Em relação à problemática do gênero, o Estado e a Nação Cabo-verdiana, desde cedo, compreenderam a importância da igualdade e da equidade de gênero para o seu processo de desenvolvimento, tendo os sucessivos governos colocados esta problemática sempre no centro das suas agendas governativas e políticas, inicialmente com a promoção e o empoderamento das mulheres e hoje orientada para a igualdade e a equidade de género.

Evidencia-se a crescente consciência, não só por parte do setor público, como também do setor privado e da sociedade civil, de que a igualdade e a equidade entre homens e mulheres são condições determinantes tanto para o sucesso e a concretização das expectativas dos cabo-verdianos como para o crescimento econômico, a coesão e a solidariedade social.

O país é portador de um quadro politico-institucional e jurídico constituído por um conjunto de instrumentos legais e de politicas setoriais que, ao longo dos tempos, vem consagrando e reafirmando a igualdade e equidade de gênero, nomeadamente, no reconhecimento dos direitos humanos das mulheres. Esse quadro é embasado por ações internacionais e nacionais.

Nesse âmbito, Cabo Verde é signatário de vários Acordos e Convenções Internacionais relacionados com a questão do género, (nomeadamente a "Convenção sobre a Eliminação de Todas as Formas de Discriminação Contra a Mulher - CEDAW", aprovada pela Assembleia Geral das Nações Unidas, em 1979, e ratificada por Cabo Verde, a 5 de Dezembro de 1980, na sua carta Magna), ou seja, a Constituição cabo-verdiana está consagrado o sistema de recepção direta, o que significa que o Direito Internacional geral ou comum e os acordos e as convenções internacionais, devidamente assinados e/ou ratificados por Cabo Verde, fazem parte integrante da ordem jurídica cabo-verdiana, enquanto vigorarem na ordem jurídica internacional.

A tomada de consciência geral sobre a questão do gênero reflete-se na criação do Instituto Nacional para Igualdade e Equidade de Gênero, entidade responsável pela "promoção da igualdade de direitos entre o homem e a mulher, a efectiva e visivel participação da mulher em todos os domínios da vida social, econômica e politica, bem assim no desenvolvimento do país" e pelo processo de implementação do II Plano Nacional para a Igualdade e Equidade de Gênero, que se distingue pela promoção da integração multisetorial da componente abordagem de gênero.

Cabo Verde, como membro de vários instrumentos políticos e jurídicos que, por essa via, de forma direta e indireta, assumem tanto obrigações relativas à gestão sustentável dos recursos hídricos e de saneamento quanto relativas a de velar e salvaguardar o direito à água e condições de salubridade ambiental tanto pelos homens e mulheres, tem vindo a elaborar políticas que levam ao uso equitativo desses bens.

Destaca-se que as organizações ligadas à problemática da igualdade de gênero, governamentais e não governamentais, desenvolvem intensas campanhas de sensibilização que advogam no sentido de introdução do princípio da paridade de gênero em todos os setores, tendo, com isto, respaldo positivo 
na disponibilização de meios de participação nos processos relacionados com a gestão dos recursos hídricos e na melhoria dos indicadores de saneamento nacionais.

Das formas de gestão dos recursos hídricos e da melhoria do saneamento, o Estado de Cabo Verde tem elaborado um conjunto de instrumentos e políticas relacionadas à gestão dos recursos naturais, mais concretamente sobre a melhoria do acesso e do uso dos recursos hídricos e da gestão do saneamento, de forma a propiciar igualdade de direitos, tanto para as mulheres quanto para os homens, no acesso a esses recursos.

Alguns programas e instrumentos de políticas foram desenvolvidos e implementados, podendose destacar o Programa Nacional de Luta contra a Pobreza (PNLP), que vem sendo executado desde 2000 a esta parte, tendo como subprogramas: i) a integração dos pobres na economia, ii) a melhoria do acesso social dos pobres, iii) a mobilização social e iv) o reforço da capacidade institucional. $O$ PNLP define como metas a atingir: a redução da taxa da pobreza, a erradicação da pobreza absoluta, a elevação do rendimento médio das camadas que vivem abaixo do limiar da pobreza, a melhoria da capacidade produtiva dos pobres, a melhoria das infraestruturas econômicas e sociais das comunidades pobres, tendo como grupos alvo prioritários: mulheres, sobretudo mulheres chefes de família; desempregados e, particularmente, jovens desempregados; grupos vulneráveis (idosos, portadores de deficiências, crianças abandonadas, inválidos). O programa focaliza a sua intervenção na construção de infraestruturas sociais, apoio à atividade econômica, apoiando áreas diversas, como a mobilização social, a formação profissional, a alfabetização, a construção de infraestruturas de abastecimento de água e de saneamento nas comunidades rurais pobres, onde o foco maior é a mulher.

Os investimentos feitos no setor de recursos hídricos e saneamento, fazendo com que o país atinja algumas metas do ODM, mostram que os efeitos positivos são sentidos por todos, reforçando, assim, a equidade e a igualdade do gênero no tocante a políticas públicas.

\subsection{Brasil e as Políticas de Gênero}

\subsection{Contexto do saneamento no Brasil}

As diretrizes nacionais para o saneamento básico foram estabelecidas pela Lei $\mathrm{N}^{\circ} 11.445$, de 05 de janeiro de 2007 (Brasil, 2007), regulamentada pelo Decreto $n^{\circ} 7.217$, de 21 de junho de 2010 (Brasil, 2010), definindo o saneamento básico como todas as ações executadas, nas áreas urbana e rural, que promovem a melhoria da drenagem pluvial, tratamento e abastecimento de água, tratamento de efluentes e manejo de resíduos sólidos. A normatização do tema, ainda que tardiamente, apresentase como importante instrumento voltado para o planejamento do setor, ancorando-se no documento referente ao Plano Nacional de Saneamento (PlanSab) e orientando que todos os municípios brasileiros realizem seus Planos Municipais de Saneamento com metas tangíveis para as quatro áreas - água, esgoto, resíduos e drenagem - a fim de serem passíveis de recebimento de financiamentos oriundos do Programa de Aceleração do Crescimento (PAC).

Denota-se que os principais investimentos realizados no setor ocorreram no período dos anos 1970/1986 à luz do Planasa (Plano Nacional de Saneamento). Até então, o setor recebia menos de $0,1 \%$ do PIB em investimentos, atingindo patamares de $0,5 \%$ do PIB no início da década de 1980 e retornando aos patamares inferiores a 1970, no início dos anos 1990.

Se, por um lado, o Planasa possibilitou a consolidação do setor de saneamento com apoio financeiro e gestão para implantação de infraestruturas de grandes obras em sistemas de abastecimento de água e coleta e transporte de esgoto, por outro lado, verificaram-se iniquidades em termos de atendimento e cobertura no que se refere às áreas urbanas e rurais. Constata-se que o perfil tecnológico desenhado e a abrangência do setor concentraram-se nas áreas urbanas centrais em detrimento da periferia das cidades e das áreas rurais.

Dados da Pesquisa Nacional de Saneamento Básico (PNAD), realizada em 2008, por exemplo, indicaram uma melhor cobertura do sistema em termos de ligações e investimentos, tanto da rede de água quanto de esgoto em áreas urbanas. Segundo a PNAD (2008), 92,8\% da população urbana acessa a rede geral como sistema de abastecimento de água, enquanto nas áreas rurais a cobertura por rede equivale a $31,5 \%$. Em termos de esgotamento sanitário, $58,9 \%$ da população urbana tem acesso a rede geral de coleta de esgoto, enquanto a cobertura nas áreas rurais atinge 5,8\%.

Tais dados nos permitem identificar que: (a) existe diferença na abrangência dos atendimentos em relação ao campo e à cidade; (b) predominam nas áreas rurais sistemas individuais e/ou alterna- 
tivos como formas de abastecimento de água e coleta de esgoto, tais como: cisternas (poços rasos) ou fossas rudimentares. Assim sendo, apesar dos diferentes avanços obtidos no sistema de infraestrutura de saneamento, notam-se iniquidades em termos de oportunidades de acesso. Tal realidade contribui para agravar situações de riscos no ambiente e na saúde, gerando maior demanda econômica, decorrente de gastos públicos, no tratamento de doenças, quando comparado aos investimentos em infraestrutura nessas áreas.

Os dados do Atlas de Saneamento do Brasil de 2011, elaborado pelo IBGE, permitem verificar o aumento na melhoria da abrangência dos serviços. Todavia, as diferenciações campo-cidade ainda persistem.

\subsubsection{Recursos hídricos e gênero no Brasil}

A relação Gênero e água ficou devidamente cunhada em 1992, na Conferência Internacional de Dublin sobre Água e Meio Ambiente, em razão da afirmação exposta no Princípio $3^{\circ}$ da declaração final da conferência, em que afirma o papel fundamental desempenhado pelas mulheres no abastecimento, na gestão e na proteção da água. A problemática da escassez dos recursos hídricos e a demanda por água levaram famílias inteiras e comunidades a adotarem diferentes estratégias para suprir essa necessidade em regiões extremamente áridas e, invariavelmente, pobres. Cenários diversos de mulheres e crianças andando percursos de três, quatro, cinco ou mais horas diárias, em regiões africanas, em busca de água para consumo, entraram para a história, demonstrando quão afetado é esse público em termos de ausência desse recurso e o papel que assumem na busca pelo mesmo. Em comunidades rurais indianas, por exemplo, mulheres "disputam", com animais, o acesso às cacimbas e outras fontes de água, que, por vezes, se encontram em situação não adequada ao consumo humano (KAPPOR, 2007).

No Brasil, tal realidade ainda é vislumbrada em regiões semiáridas do nordeste, embora, também, possa ser identificada, com distinções, nas demais regiões. O fato é que, quanto mais carente e longe de grandes centros metropolitanos for a comunidade, verifica-se maior dificuldade no acesso à água potável, quando da inexistência de oferta pública de serviços prestados. Tal realidade afeta, ainda mais, comunidades rurais, em que os sistemas de produção de água potável dificilmente atingem áreas com menor adensamento populacional em razão do aumento de custos operacionais.

Com respeito à posição do Brasil no cenário internacional, registra-se o compromisso assumido por ocasião do III Fórum Mundial da Água, Quioto, 2003, no qual o país firmou posição de incorporar a perspectiva de gênero na gestão dos recursos hídricos, como o fez também na Conferência de Bonn sobre Água Doce, conhecida como Dublin +10, em 2001. Compromissos, estes, assumidos em diferentes momentos, destacando-se a Cúpula Mundial do Desenvolvimento Sustentável, em sua Declaração Final, Princípio 18, cujas Metas para Água Potável e Saneamento, conhecidas, respectivamente, como Metas do Milênio e de Johanesburgo, visam reduzir à metade o número de pessoas sem acesso à água potável e saneamento, bem como a garantia de suprimento para atender às necessidade de água para a agricultura e alimento, permitindo às mulheres equidade no acesso ao suprimento de água e outros recursos, sendo fatores determinantes para a inclusão social e mitigação da pobreza.

Apesar dos acordos nos quais o Brasil é signatário em termos de reconhecimento da equidade de gênero, verifica-se inúmeras distinções entre homens e mulheres, quer em nível salarial, carreiras ou acesso a bens e serviços.

Dentre as políticas voltadas para o acesso à água, pode-se destacar: o projeto demonstrativo do Programa Uma Terra e Duas Águas (P1+2); o Programa Bomba D'Água Popular (BAP); o Programa Um Milhão de Cisternas $(P 1 M C)$, todos coordenados pela Articulação do Semiárido (ASA). Tais programas primam por levar água para consumo humano na região do Semiárido brasileiro, por meio do uso de tecnologias adequadas e sustentáveis de convivência com o semiárido. Os projetos visam captar água da chuva, debater sobre o uso sustentável da terra e o manejo adequado dos recursos hídricos para produção de alimentos. Elemento importante dos programas, adotado no P1MC, foi a incorporação da componente de gênero, privilegiando a participação das mulheres, especialmente, daquelas chefes de família.

Se, no Nordeste, o eixo condutor dos projetos centra-se na captação da água e na geração de renda, na região Centro-Oeste, especificamente Goiás, registram-se experiências de planejamento ambiental e gerenciamento de recursos hídricos no meio rural, cujo foco é a conservação e a utilização sustentável do Cerrado.

No Brasil, apesar de $84,35 \%$ da população morar nas áreas urbanas, tem-se quase 30 milhões 
de pessoas habitando o meio rural, distribuídas em pouco mais de oito milhões de domicílios (IBGE, 2010). As mulheres representam $43,98 \%$ da população rural; e são, em grande parte, negras ou pardas, possuem nível de escolaridade relativamente superior ao dos homens, mas, significativamente, mais baixos que as mulheres urbanas.

As mulheres possuem jornada de trabalho produtivo e reprodutivo igual e superior à masculina e encontram-se em maior situação de pobreza, com agravamento das condições para as famílias monoparentais com chefia feminina, segundo Lombardi (2009). Em termos de chefia familiar feminina, segundo o Pinheiro et al. (2008), entre 1993 e 2007, elas passaram de 22,3\% para 33\% nas famílias brasileiras. Nos assentamentos, as mudanças na forma de ingresso e reconhecimento da titularidade feminina permitiram identificar $23,06 \%$ mulheres chefes de família junto ao total de beneficiários da reforma agrária em 2007 (BUTTO \& HORA, 2008).

$\mathrm{Na}$ esfera produtiva, as mulheres dedicam-se, prioritariamente, a atividades econômicas voltadas para o autoconsumo e localizadas no entorno da residência, destacando-se atividades de: criação de pequenos animais, seguidas do cultivo de horticultura, floricultura e de atividades na lavoura. Nesta última, 54,5\% o fazem sem remuneração e, provavelmente, "ajudando" na produção familiar (LOMBARDI, 2009).

A maior presença das mulheres em atividades localizadas no entorno da casa, também, pode ser explicada pela ausência de assistência do Estado no cuidado com as crianças menores de três anos ou no apoio aos idosos. Considerando, apenas, a oferta de educação infantil ( 0 a 3 anos), verifica-se que $18,1 \%$ das crianças eram atendidas em creches no Brasil, em 2008. Na área rural, para o mesmo período, somente $7,2 \%$ eram atendidas (Inep, 2007). A falta de acesso a creches ou a políticas de amparo à terceira idade induz as mulheres a tornarem-se cuidadoras, comprometendo sua participação em atividades econômicas exercidas fora de casa. Isto, também, é externalizado na análise dos tempos dedicados aos diferentes trabalhos, por homens e mulheres. Mesmo as mulheres dedicando-se às atividades produtivas tanto ou mais tempo que os homens, estes participam muito menos do que elas nas atividades de reprodução social (Lombardi, 2009).

As condições desiguais de homens e mulheres no meio rural tem implicado na maior migração campo-cidade entre elas. Os dados do censo de 2010 apresentam que os homens são em maior número do que as mulheres no meio rural e, comparando-se os levantamentos estatísticos dos últimos anos, a migração feminina tem aumentado, resultando na diminuição percentual próximo a $5 \%$ de sua presença nas áreas rurais entre 2007 e 2010. Para Abramo (2000), a migração feminina está associada, na maioria das vezes, na busca por educação e no acesso a empregos, mesmo que de forma precária, em casas de família. Hora et al. (2011) acreditam que a permanência da precariedade no meio rural, principalmente no que tange à existência de infraestrutura básica, contribui para este fenômeno, no qual o acesso a água e ao saneamento são elementos fundamentais. Em assentamentos rurais de Goiás, por exemplo, a maior permanência de homens nas unidades produtivas familiares foram identificadas em locais destituídos de condições mínimas de saneamento (HORA et al., 2011).

\subsubsection{Institucionalização de políticas de saneamento e os desafios para incorporação do debate de gênero}

$\mathrm{Na}$ área de Saneamento, verificam-se importantes marcos recentes com a institucionalização de nova forma de gestão e instrumentos legais para alavancar o setor. Em 2003, destacou-se a criação do Ministério das Cidades com uma Secretaria Nacional de Saneamento Ambiental. Em 2004 foi criado o Conselho das cidades, viabilizando o debate em torno da política urbana com participação de diferentes atores, tais como: setor produtivo, organizações sociais, ONG's, entidades profissionais, acadêmicas e de pesquisa, entidades sindicais e órgãos governamentais. Em 2005 foi aprovada a Lei de Consórcios Públicos - Lei N ${ }^{\circ} 11.107$, de 06/04/2005, estabelecendo normas gerais de contratação de consórcios públicos, possibilitando a criação de consórcios entre os entes federados para gestão, prestação, regulação e fiscalização dos serviços de saneamento. Em 2007 foi promulgada a Lei Nacional de Saneamento Básico e demandada a realização dos Planos Municipais de Saneamento Básico com caráter participativo.

Em 2008 aprovou-se a $1^{\text {a }}$ etapa do Plansab, denominado de "Pacto pelo Saneamento Básico: Mais Saúde, Qualidade de Vida e Cidadania". O Plansab estabelece, em linhas gerais, a concepção e as diretrizes sobre o saneamento, além de marcar o início do processo de mobilização e articulação em torno dos Planos de Saneamento. Em 2010 foi aprovado o decreto $N^{o}$ 7.217, de 21/06/10, regulamentando a Lei 
de Saneamento e estabelecendo condicionantes para acesso aos recursos da União a partir de 2014. Dentre as condicionantes, constata-se: a elaboração do plano de saneamento básico pelos titulares dos serviços e a existência de controle social por órgão colegiado. Em 2010 foi aprovada a Lei $\mathrm{N}^{\circ}$ 12.305, de 02/08/2010, instituindo a Política Nacional de Resíduos Sólidos, que determina o final dos lixões em até 4 anos, regulamentada pelo Decreto $\mathrm{N}^{\mathrm{o}} 7.404$, de 23/12/2010. Enfim, foram mudanças normativas com impactos importantes na forma de gestão, realizadas recentemente.

No entanto, apesar das novas possibilidades de retomada de investimento no setor, ainda permanece o desafio em termos de atendimento, das dimensões de gênero e na abrangência dos espaços rurais. O Plansab, por exemplo, apresenta metas diferenciadas para as áreas rurais e urbanas, dado o contexto do setor de saneamento atual. No tema água, por exemplo, a universalização dos serviços para a área urbana está prevista para 2030, enquanto que na área rural, na mesma data, deve-se atingir $77 \%$ de cobertura. Em termos de esgotamento sanitário, em 2030, dever-se-á atingir $98 \%$ das áreas urbanas, enquanto as rurais alcançarão $64 \%$ no mesmo período.

No Estado de Goiás, foi institucionalizado um Grupo de Trabalho para Elaboração do Plano Estadual de Saneamento Básico em 2011, o qual encontra-se discutindo a Política Estadual de Saneamento Básico e preparando o diagnóstico do Saneamento no Estado para subsídio aos municípios. No entanto, nos debates, verifica-se dificuldade de dados em alguns temas e, especialmente, nas análises campo e cidade. Os serviços de produção de água, em 224 dos 246 municípios do estado, são realizados por Concessionária Pública Estadual, enquanto os demais possuem sistemas autônomos, sendo verificados limites na obtenção de dados em municípios pequenos e/ou com características rurais. Segundo Carvalho, 2012, os 22 são operados pelas próprias prefeituras por meio de autarquias, departamentos, secretarias ou outra forma de gestão não estruturada. Com relação aos dos serviços prestados pela Companhia Estadual nos 224 munícipios, a Agência Goiana de Regulação (AGR), criada em 2004, atua, por meio da Gerência de Saneamento, na Elaboração de regulamentações; Fiscalização da prestação dos serviços de abastecimento de água e esgotamento sanitário; Análise de solicitações de Ouvidoria; Elaboração de cálculos e estudos para Reajuste e Revisão Tarifária; Avaliação da qualidade dos serviços e Acompanhamento do cumprimento dos planos de saneamento básico elaborados pelos municípios, inclusive obras e metas de universalização. Cita, ainda, que a falta de uma estruturação da gestão do saneamento é marcada, principalmente, pela ineficiência devido a vários fatores, dentre eles problemas de planejamento, deficiência ou ausência de uma estrutura organizacional, falta de investimentos/manutenções e falta de capacitação técnica dos funcionários ou deficiência no número dos mesmos. No que se refere ao abastecimento de água, existem grandes perdas nos sistemas, além da falta de análises rotineiras de qualidade da água, dentre outros problemas. Porém, os serviços prestados por autarquias ou departamentos municipais também não estão livres de alguns desses problemas.

Sobre a situação do saneamento rural em Goiás, estudos de Hora el al. (2011; 2012) têm analisado as condições do setor nos assentamentos de reforma agrária. Em Goiás são, aproximadamente, 286 assentamentos com pouco mais de 14.500 famílias assentadas. As pesquisas denotam a ausência e/ou a insuficiência de políticas, programas e financiamento para infraestrutura de saneamento nestas áreas, aumentando a vulnerabilidade social das mulheres ali alocadas. Segundo Scalize et al. (2014), estudando o Assentamento Canudos, no estado de Goiás, concluíram, em seu trabalho, que, com exceção da captação através de mini poços, as demais captações encontram-se em situações precárias, necessitando de correções. Dessa forma, influenciando na qualidade da população local.

A insuficiência de infraestrutura de água e saneamento nos assentamentos, também, é atestada por Medeiros et al. (2004) em outras regiões do Brasil. Segundo os autores, nas áreas de reforma agrária, em 92 assentamentos investigados, apenas cinco não apresentam dificuldades no acesso à água; nos demais, constata-se a existência de lotes com problemas de falta d'água ou má qualidade da água destinada ao consumo humano; sendo que a cobertura de poços artesianos nas áreas era de $27 \%$ dos projetos analisados. Em termos de esgotamento sanitário, a situação não era diferente, apenas três assentamentos possuíam esgoto tratado nos lotes e em $80 \%$ dos casos era comum a inexistência de qualquer tipo de destino final adequado dos efluentes.

As políticas de Gênero no meio rural em geral e nos assentamentos em particular têm ofertado poucas respostas e saídas quanto à melhoria da situação do saneamento. Constatam-se ações importantíssimas, tais como o acesso a crédito produtivo, terra, assistência técnica, organizações produtivas e campanhas de enfrentamento à violência (BUTTO \& HORA, 2008; BUTTO \& DANTAS,2011), muitas das quais referenciadas no I e II Plano Nacional de Políticas para as Mulheres. No entanto, 
ainda verifica-se uma ausência e/ou insuficiência de políticas de Saneamento Rural.

\section{CONCLUSÕES, REFLEXÕES SOBRE OS RESULTADOS, PROPOSTAS AO DEBATE}

Apesar das dificuldades locais, em Cabo Verde emergem estratégias locais que visam superar as deficiências e as limitações dos sistemas por meio da gestão, principalmente, baseadas em associações cooperativadas, representadas pela experiência da Associação de Desenvolvimento Integrado de Rui Vaz. Esta associação, presidida por uma mulher, garante, a baixo custo, água para as pessoas locais e estimula a organização do trabalho em atividades agrícolas como mecanismo de geração de renda local. O trabalho, mesmo sendo de caráter individual, é realizado, predominantemente, com mão de obra feminina, garantindo às mulheres, assim, autonomia financeira.

O Brasil difere de Cabo Verde pelas suas dimensões continentais, porém há similitudes em termos de desafios internos ao setor de Água e Saneamento e quanto à superação das iniquidades em termos de abastecimento das comunidades rurais. As comunidades rurais têm baixo acesso aos serviços de abastecimento de água e esgoto. Em se tratando de comunidades localizadas em assentamentos rurais, verifica-se a dependência de estratégias individuais para suprimir a carência do serviço.

Os espaços de concertação criados, no caso cabo-verdiano, permitem internalizar o debate sobre o papel da mulher na busca por água. No Brasil, os espaços ainda são majoritariamente masculinos e aqueles destinados ao debate, exclusivamente, do papel da mulher não incorporaram o debate sobre saneamento, à exceção da experiência do PM1C quanto ao acesso à água.

Assim, as reflexões e os apontamentos permitiram identificar a necessidade de democratização do acesso às informações tanto em relação aos recursos hídricos em geral, e não apenas às fontes de captação de água, quanto ao acesso aos serviços de saneamento, compreendendo a integralidade das quatro ações (água, esgoto, drenagem e resíduos); embora o artigo pouco tenha se dedicado a resíduos e drenagem. As diferentes estratégias adotadas nas áreas visitadas, tanto em Cabo Verde quanto nos assentamentos rurais goianos, visam a ampliação do diálogo entre os muitos atores envolvidos, desde apoiadores locais até os técnicos e gestores públicos. Não obstante, o Estado precisa ter uma ação efetiva no sentido de incorporar os diferentes territórios: urbano e rural, além de oportunizar ampliação da participação das mulheres nos espaços de consertação social.

\section{AGRADECIMENTOS}

A pesquisa contou com o apoio financeiro do CNPq por meio do processo $\mathrm{CNPq}^{\circ}$ 28.087-9, a quem somos gratos.

\section{REFERÊNCIAS}

ABRAMO, L. A situação da Mulher Latino-Americana: o mercado de trabalho no contexto da reestruturação. In: DELGADO, Didice G. \& outras. Mulher e trabalho: experiências de ação afirmativa São Paulo: Boitempo, 2000. p. 111-134.

BRASIL. Lei n ${ }^{\circ} 11107$, de 6 de abril de 2005. Dispõe sobre normas gerais de contratação de consórcios públicos e dá outras providências. Brasília, 2005.

BRASIL. Lei n ${ }^{\circ} 11445$, de 05 de janeiro de 2007. Estabelece diretrizes nacionais para o saneamento básico, e dá outras providências. Brasília, 2007.

BRASIL. Decreto $\mathrm{n}^{\circ}$ 7217, de 21 de junho de 2010. Regulamenta a Lei ${ }^{\circ} 11445$, de 5 de janeiro de 2007, que estabelece diretrizes nacionais para o saneamento básico, e dá outras providências. Brasília, 2010.

Instituto Brasileiro de Geografia e Estatística (IBGE). Contagem Populacional. Censo Demográfico 2010. Dis- 
ponível em: <http://www.ibge.gov.br> Acesso em: junho/2011.

BUTTO, A. e HORA, K. E. R. Mulheres na Reforma Agrária no Brasil. In.: MDA/NEAD. Mulheres na Reforma Agrária. Brasília. p.19-38.,2008.

BUTTO, A.; DANTAS, I. Autonomia e cidadania: Políticas de organização produtiva pra as mulheres do meio rural. Brasília: Ministério do Desenvolvimento Agrário, 2011.

CABO VERDE. QUIBB 2006: Questionário Unificado de Indicadores Básicos de Bem-estar. Instituto Nacional de Estatística, Cidade da Praia, Cabo Verde, 2007.

CABO VERDE. Instituto Nacional de Estatística - INE. Recenseamento Geral da População e Habitação, Cabo Verde. Censo Geral da População e Habitação 2010. Disponível em: <http://www.ine.cv/censo/censo2010.aspx>. Acesso em 06/12/2012.

CARVALHO, A.S., SCALIZE, P.S., OLIVEIRA, R.J.. Sistemas de Saneamento em Goiás. In: Exposição de Experiências Municipais de Saneamento, XIII, 2012, Maringá - PR. 42a. Assembleia da ASSEMAE, 2012. Anais, $15 \mathrm{p}$.

FURTADO, C.A. estudo diagnóstico sobre a dimensão género na gestão integrada dos recursos hídricos em Cabo Verde, 2008. (mimeo.)

HORA, K.E.R. et al. Avaliação Ambiental Integrada de Recursos Hídricos sob a Perspectiva de Gênero: estudo de caso do Projeto de Assentamento Canudos em Goiás. In: Simpósio Brasileiro De Recursos Hídricos, XIX, 2011, Maceió, Anais, v. 1. p. 1-20.

HORA, K.E.R. et al. Saneamento Rural e Gênero em Questão: um Debate a Partir da Situação da Reforma Agrária no Brasil. In: Congresso Interamericano de Engenharia Sanitária, XXXIII, 2012, Salvador, Anais, p.1-7.

INEP. Panorama da Educação do Campo. Brasília: Instituto Nacional de Estudos e Pesquisas Educacionais Anísio Teixeira, 2007, 44p.

BRASIL. Ministério do Planejamento, Orçamento e Gestão. Instituto Brasileiro de Geografia e Estatística (IBGE). Contagem Populacional. Censo Demográfico 2010. Disponível em: < http://www.ibge.gov.br> Acesso em: junho/2011.

PINHEIRO, L. et al. Retrato das Desigualdades de Gênero e Raça. Brasília: Instituto de Pesquisa Aplicada IPEA: SPM: UNIFEM, 2008. 36p.

KAPOOR, A. (2007). Água, Mulheres e Trabalho na Zona Rural da Índia. Disponível em: http://www.pt.genderandwater.org/page/7367. Acesso em 15/06/2011.

LOMBARDI, M.R. A ocupação no setor agropecuário no período 1993-2006 e o trabalho das mulheres. In MELO e SABATO (2009). Estatísticas Rurais e a Economia Feminista: Um Olhar sobre o Trabalho das Mulheres. Brasília: MDA, 2009. 123-164p.

MEDEIROS et al. Impactos dos assentamentos: um estudo sobre o meio rural brasileiro. São Paulo: Ed. UNESP, 2004.

SCALIZE, P.S. et al. Avaliação da qualidade da água para abastecimento no assentamento de reforma agrária Canudos, Estado de Goiás. Revista Ambiente e Água, Taubaté, v. 9, n. 4, Dec. 2014, p. 696-707. http://dx.doi. org/10.4136/ambi-agua.1386 